\title{
Transgenerational inheritance of induced changes in the epigenetic state of chromatin in plants
}

\author{
Hidetoshi Saze ${ }^{1,2 *}$ \\ ${ }^{1}$ Plant Epigenetics Unit, Okinawa Institute of Science and Technology Graduate University, \\ 1919-1 Tancha, Onna-son, Okinawa 904-0495, Japan \\ ${ }^{2}$ PRESTO, Japan Science and Technology Agency (JST), \\ 4-1-8 Honcho Kawaguchi, Saitama 332-0012, Japan
}

(Received 5 March 2012, accepted 1 June 2012)

\begin{abstract}
There is growing experimental evidence from both animals and plants that changes in the environment can have profound effects on the epigenetic state of chromatin in nuclei. The epigenetic state of chromatin and the cell-specific transcription profile of genes are mitotically stable and, sometimes, can be transmitted across generations. Plants often show stable transgenerational inheritance of induced alterations of epigenetic states that are associated with morphologically or physiologically distinctive phenotypes. This pattern of inheritance may be due to the fact that germ cells produced by terminal differentiation and to the absence of appreciable epigenetic reprogramming during the life cycle. Recent advances in mass sequencing technology have accelerated the decoding of the epigenomes of various tissues and cell types and provided new insights into the dynamics of epigenetic changes during the plant life cycle and in response to environmental challenges. As plants have a sessile nature, the epigenetic regulation of genes and transposable elements in response to environmental stresses might be crucial for the generation and inheritance of phenotypic variations in plants in natural populations.
\end{abstract}

Key words: Arabidopsis thaliana, DNA methylation, environmental stress, transgenerational epigenetic inheritance, transposable elements

\section{INTRODUCTION}

The epigenetic regulation of gene expression is mediated by a variety of covalent modifications of the nucleotides and chromatin, such as methylation of cytosine residues in the DNA and post-translational alterations of core histone proteins, and also by production of small RNA molecules (Law and Jacobsen, 2010; Saze et al., 2012). Epigenetic modifications can be inherited in both a short-term (mitotic) and long-term (meiotic) manner to achieve an active or silent state in particular genes without changes to the primary DNA sequences. Specific enzymes are involved in the stable propagation of epigenetic marks during DNA replication. Importantly, the epigenetic marks are heritable but potentially reversible, which allows dynamic regulation of gene activities in response to environmental stimuli.

Cytosine methylation and covalent modifications of histone tails are key epigenetic modifications that are important for coordination of genomic integrity and proper gene

Edited by Hiroshi Iwasaki

* Corresponding author. E-mail: hidetoshi.saze@oist.jp regulation during plant development. In plant genomes, cytosine methylation can occur in all sequence contexts (i.e. $\mathrm{CG}, \mathrm{CHG}, \mathrm{CHH} ; \mathrm{H}=\mathrm{A}, \mathrm{T}$ or $\mathrm{C}$ ) and is controlled by specific DNA methyltransferases (Matzke et al., 2009; Law and Jacobsen, 2010; Saze et al., 2012). De novo methylation of unmethylated DNA is directed by an RNA interference-based mechanism named RNA-directed DNA methylation (RdDM) (Chan et al., 2005). In addition, the SWI2/SNF2-like chromatin remodeling factor DECREASE IN DNA METHYLATION 1 (DDM1) maintains CG/non-CG methylation and H3 lysine 9 methylation (Lippman et al., 2004). These marks are essential for the epigenetic silencing of transposable elements (TEs) (Kakutani et al., 2004; Law and Jacobsen, 2010). Shotgun bisulfite sequencing of the Arabidopsis thaliana genome and high-throughput sequencing of small RNAs showed that TEs and repeats accumulated in the pericentromeric regions are the primary target of DNA methylation and small interfering RNAs (siRNAs); these genomic regions are induced to form heterochromatin, a condensed and inactive chromatin structure (Cokus et al., 2008; Lister et al., 2008; Feng et al., 2010; Zemach et al., 2010). In addition to DNA methylation of TEs and repeats, plant 


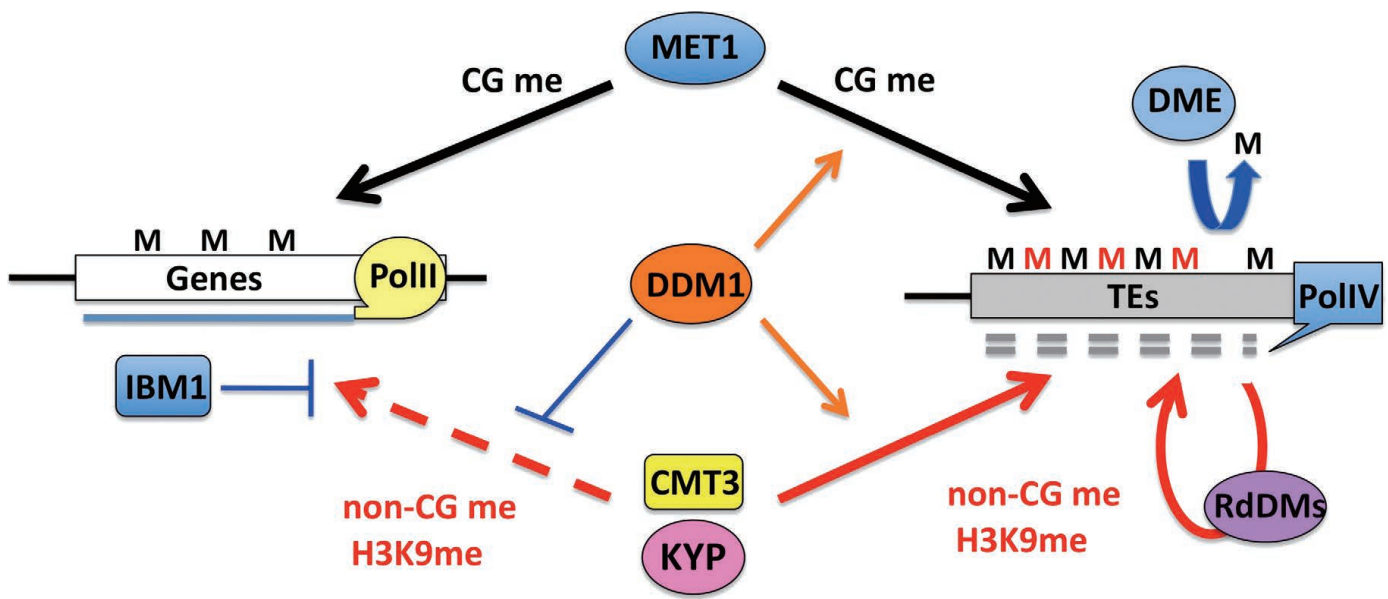

Fig. 1. A model for the differential epigenetic coordination of genes and Transposable elements (TEs). CG methylation (represented by black Ms) of both genes and TEs is maintained by METHYLTRANSFERASE1 (MET1). Non-CG methylation (red Ms) and Histone H3K9 methylation are directed by CHROMOMETHYLASE3 (CMT3) and KRYPTONITE (KYP), respectively. DECREASE IN DNA METHYLATION1 (DDM1) is required for maintenance of CG, non-CG and H3K9 methylation at TEs (Lippman et al., 2004). DDM1 is also required to prevent hypermethylation of some genic loci such as SUPERMAN or BONSAI (Saze, 2008). The pathway that directs non-CG methylation and H3K9 methylation to genic regions becomes apparent in the absence of INCREASE IN BONSAI METHYLATION1 (IBM1) (Inagaki et al., 2010; Miura et al., 2009; Saze et al., 2008) or MET1 (Cokus et al., 2008; Lister et al., 2008; Mathieu et al., 2007). DEMETER (DME) and other DNA demethylases are recruited by small-interfering RNAs (siRNAs; gray bars) and enhance production of siRNAs and RNA-directed DNA Methylation (RdDM) at TEs (Zhu, 2009). For more details on RdDM, see reviews by Law and Jacobsen (2010), Matzke et al. (2009), and Saze et al. (2012).

genomes have methylation of CG sites within actively transcribed genes (Zhang et al., 2006; Zilberman et al., 2007); gene body methylation shows evolutionary conservation in plants and animals (Feng et al., 2010; Zemach et al., 2010). Although the function of the gene body methylation is still enigmatic, DNA methylation has been shown to be preferentially targeted to the nucleosomes of exons in animals and plants, suggesting that DNA methylation has a role in exon definition (Chodavarapu et al., 2010). A recent analysis of the Arabidopsis genome showed that methylated genes are longer than unmethylated genes; methylated genes are also more functionally important and evolve more slowly (Takuno and Gaut, 2012).

In addition to epigenetic silencing mechanisms that primarily target TEs and repeat sequences, plants have evolved pathways that prevent accumulation of heterochromatic epigenetic modifications (Fig. 1). H3K9 methylation and non-CG methylation generally accumulate at repeat sequences in the pericentromeric regions (Bernatavichute et al., 2008; Cokus et al., 2008; Lister et al., 2008). The INCREASE IN BONSAI METHYLATION 1 (IBM1) gene encodes a putative H3K9 demethylase that acts specifically against H3K9 methylation and non-CG methylation of gene bodies in euchromatic regions (Saze et al., 2008; Miura et al., 2009; Inagaki et al., 2010). By contrast, the DNA demethylation pathway mediated by DNA glycosylase/lyase-type enzymes preferentially targets repetitive loci producing siRNAs (Zheng et al., 2008; Zhu, 2009); this targeted demethylation enhances production of siRNAs and reinforces the silencing of TEs (Gehring et al., 2009; Hsieh et al., 2009) (see below).

Recent advances in mass sequencing technologies combined with bisulfite analysis for DNA methylation or with Chromatin Immuno-Precipitation Sequencing (ChIP-Seq) have made it feasible to obtain the "epigenomic landscape" of particular tissues or cell types in plants (Li et al., 2008; Lister et al., 2008; Kaufmann et al., 2010; Ha et al., 2011). In this review, I mainly focus on recent progress in our understanding of the differential epigenetic regulation of genes and TEs throughout the plant life cycle, particularly in the model species Arabidopsis. Additionally, I review the evidence on the heritability of epigenetic changes, which has a potential impact on longterm phenotypic variation in plant populations.

\section{EPIGENETIC CONTROL OF TES}

The function of DNA methylation in plant genomes has been directly examined by analysis of loss-of function mutants of epigenetic modifiers such as DDM1 and METHYLTRANSFERASE 1 (MET1), a maintenance CG methylase (Vongs et al., 1993; Kankel et al., 2003; Saze et al., 2003). These studies demonstrated that the mutants induce genome-wide changes in both genetic and epigenetic contexts, which often result in the induction of developmental abnormalities (Kakutani et al., 2004; Saze, 2008). Some of the developmental abnormalities associ- 
ated with the $d d m 1$ mutation were due to new insertions of both DNA transposons and retrotransposons within development regulator genes (Miura et al., 2001; Tsukahara et al., 2009). The met 1 mutation was similarly associated with reactivation of a copia-type retrotransposon (ATCOPIA93) and a CACTA transposon (both also reactivated by $d d m 1$ ) although the effects are limited to the TEs (Mirouze et al., 2009). The distinct responses of the TE families to the mutations might be due to multiple layers of repressive epigenetic marks that prevent TEs from transposition. Indeed, some TEs show enhanced transposition ability in $d d m 1$ or met 1 plants that also carry mutations in RNAi factors or histone modifiers (Kato et al., 2003; Mirouze et al., 2009; Tsukahara et al., 2009).

Interestingly, a relatively recent amplification of the COPIA93 family seems to have occurred in A. lyrata, a close relative of $A$. thaliana. Most of these retrotransposons are integrated into centromeric satellite repeat sequences, which are gene-poor regions; this target preference would be expected to be less harmful to genes and might also be beneficial to the long-term survival of the TEs in the population (Tsukahara et al., 2009). In contrast, some types of transposons were shown to integrate into gene unit, which could alter expression patterns (Ito et al., 2011). The presence of conserved epigenetic silencing mechanisms for TEs suggests that bursts of transposon amplification would generally be harmful to the integrity of the host genome, but could allow the plants to respond to rapid changes in the environment by provide a genetic resource for restructuring genes (see below).

\section{CONTROL OF TES DURING PLANT REPRODUCTION}

It has become apparent that control of TEs by small RNAs plays an important role during plant development and reproduction (Mosher and Melnyk, 2010). The silencing of TEs by ARGONAUTE 9 (AGO9) controls female gamete formation in A. thaliana (Olmedo-Monfil et al., 2010). Mutations in AGO9 and other RNAi factors cause differentiation of multiple female gametic cells and reactivation of TEs in the egg and synergid cells before fertilization. In plants, double fertilization gives rise to the embryo and to the endosperm that nourishes the developing embryo. The endosperm displays a parent-oforigin specific pattern of expression of some genes (genomic imprinting) that is essential for proper embryogenesis; this imprinting is regulated by asymmetric DNA methylation patterns in maternal and paternal alleles (Ikeda and Kinoshita, 2009; Jullien and Berger, 2009). The DNA demethylase DEMETER (DME) demethylates maternal alleles in the endosperm, ensuring maternal allele-specific expression of imprinted genes (Kinoshita et al., 2004; Gehring et al., 2006; Hsieh et al., 2011). DNA methylation profiling of the Arabidopsis endosperm genome showed that the reduction in DNA methylation occurs throughout the genome, but particularly at TE sequences (Gehring et al., 2009; Hsieh et al., 2009). CG methylation in the dme endosperm is higher in TEs and genes than in the wild type endosperm, while non-CG methylation is reduced in the $d m e$ endosperm compared to the wild type. The latter might be a consequence of a lower level of TE-mediated production of siRNAs that normally reinforce non-CG methylation and silencing of TEs in the endosperm and possibly also the embryo (Hsieh et al., 2009). Furthermore, in parallel with the global reduction in DNA methylation in the endosperm, a large increase in the production of siRNAs from maternal chromosomes was observed in developing seeds (Mosher et al., 2009, 2011).

Intriguingly, an analogous mechanism may operate in anthers during pollen maturation. A pollen grain has one vegetative cell nucleus (VN) that is not transmitted to the next generation, and two sperm cell nuclei (SN): one SN fertilizes the egg cell, the other fuses to the central cell of the embryo sac to give rise to the endosperm. The VN shows extensive decondensation of centromeric chromatin along with a reduction in H3K9 methylation (Schoft et al., 2009). TEs are activated and transposed in the $\mathrm{VN}$; this behavior coincides with downregulation of DDM1 and active expression of DME in the VN (Slotkin et al., 2009; Schoft et al., 2011). The small RNAs produced in the VN may be transported to the gametes through cytoplasmic connection and direct silencing of their TEs (Borges et al., 2011; McCue et al., 2011, 2012).

These studies have provided new insights into the function of germline companion cells with regard to the control of TEs in the genome through their production of siRNAs to inactivate TE activity in gametes. Interestingly, transgene-derived and endogenous siRNAs, derived principally from TEs and methylated regions, can both travel systemically through the phloem and direct RdDM to homologous target genes in remote cells (Dunoyer et al., 2010a, 2010b; Molnar et al., 2010; Melnyk et al., 2011). The details of the transportation mechanism that moves mobile siRNAs through the nuclear envelope to chromatin is still unclear; however, such mobile siRNAs offer a possible mechanism for "synchronization" of the epigenetic state of TEs not only in somatic cells but also in gametes to prevent germline transmission and propagation of active TEs in the population.

\section{STRESS RESPONSES AND EPIGENETIC CHANGES}

There has been a number of observations in plants and animals showing that environmental stresses can induce genetic and epigenetic changes that may be a source of phenotypic variation in the population (Boyko and 
Kovalchuk, 2011; Feil and Fraga, 2012; Mirouze and Paszkowski, 2011). In plants, epigenetic changes can drastically affect plant morphology and physiology (Cubas et al., 1999; Manning et al., 2006; Martin et al., 2009; Lira-Medeiros et al., 2010; Paun et al., 2010). However, the underlying molecular mechanisms/pathways by which environmental cues influence the epigenetic status of chromatin remain elusive. Furthermore, the transgenerational effects of stress-induced epigenetic changes have been questioned so far in plants (Pecinka and Mittelsten Scheid, 2012). For example, in A. thaliana, a prolonged period of cold treatment of plants, called vernalization, induces repression of a MADS box gene $F L C$ (Flowering Locus $C$ ) and promotes flowering (Amasino, 2005; Baurle and Dean, 2006; Dennis and Peacock, 2007). The repression of $F L C$ is mediated by PcG complex that deposit H3K27 methylation on FLC locus. The epigenetic state of $F L C$ is stably transmitted through mitosis, but not meiosis, and is reset in every generation. Environmental stress such as prolonged heat treatment can cause a transient de-repression of the silencing of transgenes and of endogenous TEs in constitutive heterochromatin (Lang-Mladek et al., 2010; Pecinka et al., 2010; Tittel-Elmer et al., 2010). Interestingly, although the derepression was associated with a loss of heterochromatic structure, it was not accompanied by changes in epigenetic modifications such as DNA methylation or histone modification, and was restored relatively quickly to the initial silent state. The efficiency of restoration is impaired in plants with mutations affecting aspects of chromatin assembly, indicating that the de novo nucleosome assembly pathway at heterochromatic loci is essential for the reestablishment of the initial silencing state (Pecinka et al., 2010). Similarly, transient reactivation and movement of a copia-type endogenous retrotransposon (named ONSEN) can also be induced in plants with an impaired RNA interference machinery that are placed under a heat stress (Ito et al., 2011; Matsunaga et al., 2012).

\section{STABILITY OF EPIGENETIC ALLELES AND TRANSGENERATIONAL EPIGENETIC INHERITANCE OF PHENOTYPIC VARIATIONS INDUCED BY MUTATIONS OF EPIGENETIC MODIFIERS}

Epigenetic alleles (epi-alleles) induced by mutations of epigenetic modifiers are sometimes associated with changes in gene expression that lead to abnormal phenotypes during development (Henderson and Jacobsen, 2008; Saze, 2008). The epi-allele formation is often related to a destruction of epigenetic control of TEs (Lippman et al., 2004; Kinoshita et al., 2007; Saze and Kakutani, 2007; Fujimoto et al., 2008). Once established, the altered epigenetic state can be maintained through mitoses and often across generations. In plants,
DNA methylation patterns can be maintained through several rounds of DNA replication by maintenance DNA methylase and DNA binding proteins, as has also been found in mammals (Bostick et al., 2007; Sharif et al., 2007). In addition, histone-based inheritance of the epigenetic state might occur during DNA replication (Moazed, 2011). The transgenerational stabilities of epialleles were examined in epigenetic recombinant inbred lines (epiRILs) of A. thaliana generated by crossing met 1 or $d d m 1$ mutants to the isogenic wild type strain (Johannes et al., 2009; Reinders et al., 2009; Teixeira et al., 2009). In general, DNA methylation patterns showed stable inheritance and the epigenetic marks on chromosomes were transmitted over several generations. However, in $d d m 1$-derived epiRILs, a progressive DNA remethylation occurred at repeat sequences associated with siRNAs. Unexpectedly, in met1-derived epiRILs, nonparental DNA methylation patterns not related to the methylation profiles of the parental chromosomes were identified. This intriguing phenomenon in met1-derived epiRILs might be the result of an RNAi-based remethylation mechanism or a "back-up" mechanism of DNA methylation upon the genome-wide loss of CG methylation (Mathieu et al., 2007). The epiRIL populations exhibited continuous phenotypic variation for important complex quantitative traits including flowering time, plant height, biomass, and responses to both abiotic and biotic stresses (Johannes et al., 2009; Reinders et al., 2009). Furthermore, some of these phenotypic variations were stably inherited by the next generation, confirming the potential of epigenetic variation to contribute to heritable phenotypic variation.

Recent studies examined the spontaneous loss or gain of DNA methylation and its stability across generations in A. thaliana experimental lines propagated by singleseed descent for more than 30 generations (Becker et al., 2011; Schmitz et al., 2011). CG methylation varied in gene-rich regions of the genome, whereas $\mathrm{CG}$ and non-CG methylation of TEs were relatively stable. The stable inheritance of DNA methylation at TEs may occur because of a close association of 24-nucleotide siRNAs to TEs that reinforces de novo DNA methylation. Schmitz et al. (2011) estimated a minimum level for epi-mutation of $4.5 \times 10^{-4}$ methylation polymorphisms per site per generation; this estimate is orders of magnitude higher than the estimated genetic mutation rate of $7 \times 10^{-9}$ base substitution rate per site per generation in the same Arabidopsis experimental population (Ossowski et al., 2010; Becker et al., 2011). Alteration of DNA methylation patterns at some loci were associated with changes in gene expression levels, whereas other loci did not show a significant alteration in expression in response to the methylation changes, indicating the complexity of the effects of DNA methylation and other epigenetic marks on gene transcription behavior. 


\section{CONCLUSION AND PERSPECTIVES}

There is growing evidence that environmentally induced heritable changes to the epigenome are common in both plants and animals (Carone et al., 2010; Feil and Fraga, 2012; Seong et al., 2011; Daxinger and Whitelaw, 2012). However, because of the plastic nature of the epigenome, it is still not clear whether such environmentally induced changes are a reflection of a temporary acclimation to the environment or have evolutionary consequences, i.e., alteration of the primary DNA sequence. It is known that 5 -methyl cytosine $(5 \mathrm{mC})$ has a potentially high rate of mutagenic changes (i.e., spontaneous deamination of $5 \mathrm{mC}$ results in $\mathrm{C}$ to $\mathrm{T}$ substitution) (Turner, 2009). In addition, stress-induced activation and insertion of TEs in or near genes may cause modulation of cellular transcriptomes as well as new gene formation by exonization (Cordaux and Batzer, 2009; Matsunaga et al., 2012). The "domestication" of TEs in the genome could thus be essential for future genomic stability particularly after structural reorganization events in the genome such as polyploidization and hybrid formation (Chen et al., 2008; Chang et al., 2010; Pignatta et al., 2010; Fujimoto et al., 2011; Greaves et al., 2012; Shen et al., 2012). In addition to genomic DNA, it is possible that small RNA molecules could act as a transmitter of extragenic information on the surrounding environment to the progeny. For example, virus-derived small-interfering RNAs can mediate a transgenerational antiviral response in Caenorhabditis elegans, showing the inheritance of an "acquired trait" across generations (Rechavi et al., 2011). Although it is yet unclear in plants, translocation of mobile small RNAs from somatic cells to shoot meristems and eventually to germlines could affect epigenetic inheritance of phenotypic variations (Martienssen, 2010). Thus, unveiling the molecular mechanisms of transgenerational epigenetic inheritance is an important future research area. In addition, molecular evidence for pathways and factors via which environmental cues influence chromatin structure will provide further insights into stress-induced epigenetic changes and their transgenerational consequences, which should occur frequently under natural environment.

H.S. is supported by Japan Science and Technology Agency (JST) PRESTO program.

\section{REFERENCES}

Amasino, R. M. (2005) Vernalization and flowering time. Curr. Opin. Biotechnol. 16, 154-158.

Baurle, I., and Dean, C. (2006) The timing of developmental transitions in plants. Cell 125, 655-664.

Becker, C., Hagmann, J., Muller, J., Koenig, D., Stegle, O., Borgwardt, K., and Weigel, D. (2011) Spontaneous epigenetic variation in the Arabidopsis thaliana methylome.
Nature 480, 245-249.

Bernatavichute, Y. V., Zhang, X., Cokus, S., Pellegrini, M., and Jacobsen, S. E. (2008) Genome-wide association of histone H3 lysine nine methylation with CHG DNA methylation in Arabidopsis thaliana. PLoS One 3, e3156.

Borges, F., Pereira, P. A., Slotkin, R. K., Martienssen, R. A., and Becker, J. D. (2011) MicroRNA activity in the Arabidopsis male germline. J. Exp. Bot. 62, 1611-1620.

Bostick, M., Kim, J. K., Esteve, P. O., Clark, A., Pradhan, S., and Jacobsen, S. E. (2007) UHRF1 plays a role in maintaining DNA methylation in mammalian cells. Science 317, 1760-1764.

Boyko, A., and Kovalchuk, I. (2011) Genome instability and epigenetic modification-heritable responses to environmental stress? Curr. Opin. Plant Biol. 14, 260-266.

Carone, B. R., Fauquier, L., Habib, N., Shea, J. M., Hart, C. E., Li, R., Bock, C., Li, C., Gu, H., Zamore, P. D., et al. (2010) Paternally induced transgenerational environmental reprogramming of metabolic gene expression in mammals. Cell 143, 1084-1096.

Chan, S. W., Henderson, I. R., and Jacobsen, S. E. (2005) Gardening the genome: DNA methylation in Arabidopsis thaliana. Nat. Rev. Genet. 6, 351-360.

Chang, P. L., Dilkes, B. P., McMahon, M., Comai, L., and Nuzhdin, S. V. (2010) Homoeolog-specific retention and use in allotetraploid Arabidopsis suecica depends on parent of origin and network partners. Genome Biol. 11, R125.

Chen, M., Ha, M., Lackey, E., Wang, J., and Chen, Z. J. (2008) RNAi of met1 reduces DNA methylation and induces genome-specific changes in gene expression and centromeric small RNA accumulation in Arabidopsis allopolyploids. Genetics 178, 1845-1858.

Chodavarapu, R. K., Feng, S., Bernatavichute, Y. V., Chen, P. Y., Stroud, H., Yu, Y., Hetzel, J. A., Kuo, F., Kim, J., Cokus, S. J., et al. (2010) Relationship between nucleosome positioning and DNA methylation. Nature 466, 388-392.

Cokus, S. J., Feng, S., Zhang, X., Chen, Z., Merriman, B., Haudenschild, C. D., Pradhan, S., Nelson, S. F., Pellegrini, M., and Jacobsen, S. E. (2008) Shotgun bisulphite sequencing of the Arabidopsis genome reveals DNA methylation patterning. Nature 452, 215-219.

Cordaux, R., and Batzer, M. A. (2009) The impact of retrotransposons on human genome evolution. Nat. Rev. Genet. 10, 691-703.

Cubas, P., Vincent, C., and Coen, E. (1999) An epigenetic mutation responsible for natural variation in floral symmetry. Nature 401, 157-161.

Daxinger, L., and Whitelaw, E. (2012) Understanding transgenerational epigenetic inheritance via the gametes in mammals. Nat. Rev. Genet. 13, 153-162.

Dennis, E. S., and Peacock, W. J. (2007) Epigenetic regulation of flowering. Curr. Opin. Plant Biol. 10, 520-527.

Dunoyer, P., Brosnan, C. A., Schott, G., Wang, Y., Jay, F., Alioua, A., Himber, C., and Voinnet, O. (2010a) An endogenous, systemic RNAi pathway in plants. EMBO J. 29, 1699-1712.

Dunoyer, P., Schott, G., Himber, C., Meyer, D., Takeda, A., Carrington, J. C., and Voinnet, O. (2010b) Small RNA duplexes function as mobile silencing signals between plant cells. Science 328, 912-916.

Feil, R., and Fraga, M. F. (2012) Epigenetics and the environment: emerging patterns and implications. Nat. Rev. Genet. 13, 97-109.

Feng, S., Cokus, S. J., Zhang, X., Chen, P. Y., Bostick, M., Goll, M. G., Hetzel, J., Jain, J., Strauss, S. H., Halpern, M. E., et 
al. (2010) Conservation and divergence of methylation patterning in plants and animals. Proc. Natl. Acad. Sci. USA 107, 8689-8694.

Fujimoto, R., Kinoshita, Y., Kawabe, A., Kinoshita, T., Takashima, K., Nordborg, M., Nasrallah, M. E., Shimizu, K. K., Kudoh, H., and Kakutani, T. (2008) Evolution and control of imprinted FWA genes in the genus Arabidopsis. PLoS Genet. 4, e1000048.

Fujimoto, R., Taylor, J. M., Sasaki, T., Kawanabe, T., and Dennis, E. S. (2011) Genome wide gene expression in artificially synthesized amphidiploids of Arabidopsis. Plant. Mol. Biol. 77, 419-431.

Gehring, M., Huh, J. H., Hsieh, T. F., Penterman, J., Choi, Y., Harada, J. J., Goldberg, R. B., and Fischer, R. L. (2006) DEMETER DNA glycosylase establishes MEDEA polycomb gene self-imprinting by allele-specific demethylation. Cell 124, 495-506.

Gehring, M., Bubb, K. L., and Henikoff, S. (2009) Extensive demethylation of repetitive elements during seed development underlies gene imprinting. Science 324, 1447-1451.

Greaves, I. K., Groszmann, M., Ying, H., Taylor, J. M., Peacock, W. J., and Dennis, E. S. (2012) Trans chromosomal methylation in Arabidopsis hybrids. Proc. Natl. Acad. Sci. USA 109, 3570-3575.

Ha, M., Ng, D. W., Li, W. H., and Chen, Z. J. (2011) Coordinated histone modifications are associated with gene expression variation within and between species. Genome Res. 21, $590-598$

Henderson, I. R., and Jacobsen, S. E. (2008) Tandem repeats upstream of the Arabidopsis endogene SDC recruit non-CG DNA methylation and initiate siRNA spreading. Genes Dev. 22, 1597-1606.

Hsieh, T. F., Ibarra, C. A., Silva, P., Zemach, A., EshedWilliams, L., Fischer, R. L., and Zilberman, D. (2009) Genome-wide demethylation of Arabidopsis endosperm. Science 324, 1451-1454.

Hsieh, T. F., Shin, J., Uzawa, R., Silva, P., Cohen, S., Bauer, M. J., Hashimoto, M., Kirkbride, R. C., Harada, J. J., Zilberman, D., et al. (2011) Regulation of imprinted gene expression in Arabidopsis endosperm. Proc. Natl. Acad. Sci. USA 108, 1755-1762.

Ikeda, Y., and Kinoshita, T. (2009) DNA demethylation: a lesson from the garden. Chromosoma 118, 37-41.

Inagaki, S., Miura-Kamio, A., Nakamura, Y., Lu, F., Cui, X., Cao, X., Kimura, H., Saze, H., and Kakutani, T. (2010) Autocatalytic differentiation of epigenetic modifications within the Arabidopsis genome. EMBO J. 29, 3496-3506.

Ito, H., Gaubert, H., Bucher, E., Mirouze, M., Vaillant, I., and Paszkowski, J. (2011) An siRNA pathway prevents transgenerational retrotransposition in plants subjected to stress. Nature 472, 115-119.

Johannes, F., Porcher, E., Teixeira, F. K., Saliba-Colombani, V., Simon, M., Agier, N., Bulski, A., Albuisson, J., Heredia, F., Audigier, P., et al. (2009) Assessing the impact of transgenerational epigenetic variation on complex traits. PLoS Genet. 5, e1000530.

Jullien, P. E., and Berger, F. (2009) Gamete-specific epigenetic mechanisms shape genomic imprinting. Curr. Opin. Plant Biol. 12, 637-642.

Kakutani, T., Kato, M., Kinoshita, T., and Miura, A. (2004) Control of development and transposon movement by DNA methylation in Arabidopsis thaliana. Cold Spring Harb. Symp. Quant. Biol. 69, 139-143.

Kankel, M. W., Ramsey, D. E., Stokes, T. L., Flowers, S. K., Haag, J. R., Jeddeloh, J. A., Riddle, N. C., Verbsky, M. L., and Richards, E. J. (2003) Arabidopsis MET1 cytosine methyltransferase mutants. Genetics 163, 1109-1122.

Kato, M., Miura, A., Bender, J., Jacobsen, S. E., and Kakutani, T. (2003) Role of CG and non-CG methylation in immobilization of transposons in Arabidopsis. Curr. Biol. 13, 421426.

Kaufmann, K., Muino, J. M., Osteras, M., Farinelli, L., Krajewski, P., and Angenent, G. C. (2010) Chromatin immunoprecipitation (ChIP) of plant transcription factors followed by sequencing (ChIP-SEQ) or hybridization to whole genome arrays (ChIP-CHIP). Nat. Protoc. 5, 457-472.

Kinoshita, T., Miura, A., Choi, Y., Kinoshita, Y., Cao, X., Jacobsen, S. E., Fischer, R. L., and Kakutani, T. (2004) One-way control of FWA imprinting in Arabidopsis endosperm by DNA methylation. Science 303, 521-523.

Kinoshita, Y., Saze, H., Kinoshita, T., Miura, A., Soppe, W. J., Koornneef, M., and Kakutani, T. (2007) Control of FWA gene silencing in Arabidopsis thaliana by SINE-related direct repeats. Plant J. 49, 38-45.

Lang-Mladek, C., Popova, O., Kiok, K., Berlinger, M., Rakic, B., Aufsatz, W., Jonak, C., Hauser, M. T., and Luschnig, C. (2010) Transgenerational inheritance and resetting of stress-induced loss of epigenetic gene silencing in Arabidopsis. Mol. Plant 3, 594-602.

Law, J. A., and Jacobsen, S. E. (2010) Establishing, maintaining and modifying DNA methylation patterns in plants and animals. Nat. Rev. Genet. 11, 204-220.

Li, X., Wang, X., He, K., Ma, Y., Su, N., He, H., Stolc, V., Tongprasit, W., Jin, W., Jiang, J., et al. (2008) High-resolution mapping of epigenetic modifications of the rice genome uncovers interplay between DNA methylation, histone methylation, and gene expression. Plant Cell 20, 259-276.

Lippman, Z., Gendrel, A. V., Black, M., Vaughn, M. W., Dedhia, N., McCombie, W. R., Lavine, K., Mittal, V., May, B., Kasschau, K. D., et al. (2004) Role of transposable elements in heterochromatin and epigenetic control. Nature $\mathbf{4 3 0}$, 471-476.

Lira-Medeiros, C. F., Parisod, C., Fernandes, R. A., Mata, C. S., Cardoso, M. A., and Ferreira, P. C. (2010) Epigenetic variation in mangrove plants occurring in contrasting natural environment. PLoS One 5, e10326.

Lister, R., O’Malley, R. C., Tonti-Filippini, J., Gregory, B. D., Berry, C. C., Millar, A. H., and Ecker, J. R. (2008) Highly integrated single-base resolution maps of the epigenome in Arabidopsis. Cell 133, 523-536.

Manning, K., Tor, M., Poole, M., Hong, Y., Thompson, A. J., King, G. J., Giovannoni, J. J., and Seymour, G. B. (2006) A naturally occurring epigenetic mutation in a gene encoding an SBP-box transcription factor inhibits tomato fruit ripening. Nat. Genet. 38, 948-952.

Martienssen, R. (2010) Molecular biology. Small RNA makes its move. Science 328, 834-835.

Martin, A., Troadec, C., Boualem, A., Rajab, M., Fernandez, R. Morin, H., Pitrat, M., Dogimont, C., and Bendahmane, A (2009) A transposon-induced epigenetic change leads to sex determination in melon. Nature 461, 1135-1138.

Mathieu, O., Reinders, J., Caikovski, M., Smathajitt, C., and Paszkowski, J. (2007) Transgenerational stability of the Arabidopsis epigenome is coordinated by CG methylation. Cell 130, 851-862

Matsunaga, W., Kobayashi, A., Kato, A., and Ito, H. (2012) The effects of heat induction and the siRNA biogenesis pathway on the transgenerational transposition of ONSEN, a copialike retrotransposon in Arabidopsis thaliana. Plant Cell Physiol. 53, 824-833. 
Matzke, M., Kanno, T., Daxinger, L., Huettel, B., and Matzke, A. J. (2009) RNA-mediated chromatin-based silencing in plants. Curr. Opin. Cell Biol. 21, 367-376.

McCue, A. D., Cresti, M., Feijo, J. A., and Slotkin, R. K. (2011) Cytoplasmic connection of sperm cells to the pollen vegetative cell nucleus: potential roles of the male germ unit revisited. J. Exp. Bot. 62, 1621-1631.

McCue, A. D., Nuthikattu, S., Reeder, S. H., and Slotkin, R. K. (2012) Gene expression and stress response mediated by the epigenetic regulation of a transposable element small RNA. PLoS Genet. 8, e1002474.

Melnyk, C. W., Molnar, A., Bassett, A., and Baulcombe, D. C. (2011) Mobile $24 \mathrm{nt}$ small RNAs direct transcriptional gene silencing in the root meristems of Arabidopsis thaliana. Curr. Biol. 21, 1678-1683.

Mirouze, M., and Paszkowski, J. (2011) Epigenetic contribution to stress adaptation in plants. Curr. Opin. Plant Biol. 14, $267-274$

Mirouze, M., Reinders, J., Bucher, E., Nishimura, T., Schneeberger, K., Ossowski, S., Cao, J., Weigel, D., Paszkowski, J., and Mathieu, O. (2009) Selective epigenetic control of retrotransposition in Arabidopsis. Nature 461, $427-430$.

Miura, A., Yonebayashi, S., Watanabe, K., Toyama, T., Shimada, H., and Kakutani, T. (2001) Mobilization of transposons by a mutation abolishing full DNA methylation in Arabidopsis. Nature 411, 212-214.

Miura, A., Nakamura, M., Inagaki, S., Kobayashi, A., Saze, H., and Kakutani, T. (2009) An Arabidopsis jmjC domain protein protects transcribed genes from DNA methylation at CHG sites. EMBO J. 28, 1078-1086.

Moazed, D. (2011) Mechanisms for the inheritance of chromatin states. Cell 146, 510-518.

Molnar, A., Melnyk, C. W., Bassett, A., Hardcastle, T. J., Dunn, R., and Baulcombe, D. C. (2010) Small silencing RNAs in plants are mobile and direct epigenetic modification in recipient cells. Science 328, 872-875.

Mosher, R. A., and Melnyk, C. W. (2010) siRNAs and DNA methylation: seedy epigenetics. Trends Plant Sci. 15, 204210.

Mosher, R. A., Melnyk, C. W., Kelly, K. A., Dunn, R. M., Studholme, D. J., and Baulcombe, D. C. (2009) Uniparental expression of PolIV-dependent siRNAs in developing endosperm of Arabidopsis. Nature 460, 283-286.

Mosher, R. A., Tan, E. H., Shin, J., Fischer, R. L., Pikaard, C. S., and Baulcombe, D. C. (2011) An atypical epigenetic mechanism affects uniparental expression of Pol IV-dependent siRNAs. PLoS One 6, e25756.

Olmedo-Monfil, V., Duran-Figueroa, N., Arteaga-Vazquez, M., Demesa-Arevalo, E., Autran, D., Grimanelli, D., Slotkin, R. K., Martienssen, R. A., and Vielle-Calzada, J. P. (2010) Control of female gamete formation by a small RNA pathway in Arabidopsis. Nature 464, 628-632.

Ossowski, S., Schneeberger, K., Lucas-Lledo, J. I., Warthmann, N., Clark, R. M., Shaw, R. G., Weigel, D., and Lynch, M. (2010) The rate and molecular spectrum of spontaneous mutations in Arabidopsis thaliana. Science 327, 92-94.

Paun, O., Bateman, R. M., Fay, M. F., Hedren, M., Civeyrel, L., and Chase, M. W. (2010) Stable epigenetic effects impact adaptation in allopolyploid orchids (Dactylorhiza: Orchidaceae). Mol. Biol. Evol. 27, 2465-2473.

Pecinka, A., and Mittelsten Scheid, O. (2012) Stress-induced chromatin changes: a critical view on their heritability. Plant Cell Physiol. 53, 801-808.

Pecinka, A., Dinh, H. Q., Baubec, T., Rosa, M., Lettner, N., and
Mittelsten Scheid, O. (2010) Epigenetic regulation of repetitive elements is attenuated by prolonged heat stress in Arabidopsis. Plant Cell 22, 3118-3129.

Pignatta, D., Dilkes, B. P., Yoo, S. Y., Henry, I. M., Madlung, A., Doerge, R. W., Jeffrey Chen, Z., and Comai, L. (2010) Differential sensitivity of the Arabidopsis thaliana transcriptome and enhancers to the effects of genome doubling. New Phytol. 186, 194-206.

Rechavi, O., Minevich, G., and Hobert, O. (2011) Transgenerational inheritance of an acquired small RNA-based antiviral response in C. elegans. Cell 147, 1248-1256.

Reinders, J., Wulff, B. B., Mirouze, M., Mari-Ordonez, A., Dapp, M., Rozhon, W., Bucher, E., Theiler, G., and Paszkowski, J. (2009) Compromised stability of DNA methylation and transposon immobilization in mosaic Arabidopsis epigenomes. Genes Dev. 23, 939-950.

Saze, H. (2008) Epigenetic memory transmission through mitosis and meiosis in plants. Semin. Cell Dev. Biol. 19, 527536.

Saze, H., and Kakutani, T. (2007) Heritable epigenetic mutation of a transposon-flanked Arabidopsis gene due to lack of the chromatin-remodeling factor DDM1. EMBO J. 26, 36413652 .

Saze, H., Mittelsten Scheid, O., and Paszkowski, J. (2003) Maintenance of $\mathrm{CpG}$ methylation is essential for epigenetic inheritance during plant gametogenesis. Nat. Genet. 34, $65-69$.

Saze, H., Shiraishi, A., Miura, A., and Kakutani, T. (2008) Control of genic DNA methylation by a jmjC domain-containing protein in Arabidopsis thaliana. Science 319, 462-465.

Saze, H., Tsugane, K., Kanno, T., and Nishimura, T. (2012) DNA methylation in plants: Relationship with small RNAs and histone modifications, and functions in Ttransposon inactivation. Plant Cell Physiol. 53, 766-784.

Schmitz, R. J., Schultz, M. D., Lewsey, M. G., O’Malley, R. C., Urich, M. A., Libiger, O., Schork, N. J., and Ecker, J. R. (2011) Transgenerational epigenetic instability is a source of novel methylation variants. Science 334, 369-373.

Schoft, V. K., Chumak, N., Mosiolek, M., Slusarz, L., Komnenovic, V., Brownfield, L., Twell, D., Kakutani, T., and Tamaru, H. (2009) Induction of RNA-directed DNA methylation upon decondensation of constitutive heterochromatin. EMBO Rep. 10, 1015-1021.

Schoft, V. K., Chumak, N., Choi, Y., Hannon, M., Garcia-Aguilar, M., Machlicova, A., Slusarz, L., Mosiolek, M., Park, J. S., Park, G. T., et al. (2011) Function of the DEMETER DNA glycosylase in the Arabidopsis thaliana male gametophyte. Proc. Natl. Acad. Sci. USA 108, 8042-8047.

Seong, K. H., Li, D., Shimizu, H., Nakamura, R., and Ishii, S. (2011) Inheritance of stress-induced, ATF-2-dependent epigenetic change. Cell 145, 1049-1061.

Sharif, J., Muto, M., Takebayashi, S., Suetake, I., Iwamatsu, A., Endo, T. A., Shinga, J., Mizutani-Koseki, Y., Toyoda, T., Okamura, K., et al. (2007) The SRA protein Np95 mediates epigenetic inheritance by recruiting Dnmt1 to methylated DNA. Nature 450, 908-912.

Shen, H., He, H., Li, J., Chen, W., Wang, X., Guo, L., Peng, Z., He, G., Zhong, S., Qi, Y., et al. (2012) Genome-wide analysis of DNA methylation and gene expression changes in two Arabidopsis ecotypes and their reciprocal hybrids. Plant Cell 24, 875-892.

Slotkin, R. K., Vaughn, M., Borges, F., Tanurdzic, M., Becker, J. D., Feijo, J. A., and Martienssen, R. A. (2009) Epigenetic reprogramming and small RNA silencing of transposable elements in pollen. Cell 136, 461-472. 
Takuno, S., and Gaut, B. S. (2012) Body-methylated genes in Arabidopsis thaliana are functionally important and evolve slowly. Mol. Biol. Evol. 29, 219-227.

Teixeira, F. K., Heredia, F., Sarazin, A., Roudier, F., Boccara, M., Ciaudo, C., Cruaud, C., Poulain, J., Berdasco, M., Fraga, M. F., et al. (2009) A role for RNAi in the selective correction of DNA methylation defects. Science 323, 1600-1604.

Tittel-Elmer, M., Bucher, E., Broger, L., Mathieu, O., Paszkowski, J., and Vaillant, I. (2010) Stress-induced activation of heterochromatic transcription. PLoS Genet. 6, e1001175.

Tsukahara, S., Kobayashi, A., Kawabe, A., Mathieu, O., Miura, A., and Kakutani, T. (2009) Bursts of retrotransposition reproduced in Arabidopsis. Nature 461, 423-426.

Turner, B. M. (2009) Epigenetic responses to environmental change and their evolutionary implications. Phil. Trans. R. Soc. Lond. B 364, 3403-3418.

Vongs, A., Kakutani, T., Martienssen, R. A., and Richards, E. J. (1993) Arabidopsis thaliana DNA methylation mutants. Science 260, 1926-1928.
Zemach, A., McDaniel, I. E., Silva, P., and Zilberman, D. (2010) Genome-wide evolutionary analysis of eukaryotic DNA methylation. Science 328, 916-919.

Zhang, X., Yazaki, J., Sundaresan, A., Cokus, S., Chan, S. W., Chen, H., Henderson, I. R., Shinn, P., Pellegrini, M., Jacobsen, S. E., et al. (2006) Genome-wide high-resolution mapping and functional analysis of DNA methylation in Arabidopsis. Cell 126, 1189-1201.

Zheng, X., Pontes, O., Zhu, J., Miki, D., Zhang, F., Li, W. X., Iida, K., Kapoor, A., Pikaard, C. S., and Zhu, J. K. (2008) ROS3 is an RNA-binding protein required for DNA demethylation in Arabidopsis. Nature 455, 1259-1262.

Zhu, J. K. (2009) Active DNA demethylation mediated by DNA glycosylases. Annu. Rev. Genet. 43, 143-166.

Zilberman, D., Gehring, M., Tran, R. K., Ballinger, T., and Henikoff, S. (2007) Genome-wide analysis of Arabidopsis thaliana DNA methylation uncovers an interdependence between methylation and transcription. Nat. Genet. 39, 61-69. 